DOI: 10.11606/issn.2238-3867.v16i1p71-81

sala preta

ppgac

Dossiê Performatividades Originárias

\title{
Circo: risco, performatividade e resistência
}

Circus: risk, performativity and resistance

\section{Carolina Hamanaka Mandell}

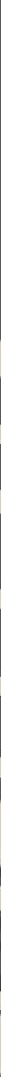

Atriz, performer, arte-educadora. Graduada em Artes Cênicas pela Unicamp. Mestre em Pedagogia Teatral pela

ECA-USP. Doutoranda em Artes da Cena pela Unicamp

e artista pesquisadora do Lume - Núcleo de Pesquisas Teatrais (Unicamp), vinculada ao projeto "Presença e Vida" na linha de Pesquisas Técnicas e Processos de Formação

do Artista da Cena 


\section{Resumo}

Este artigo busca o levantamento de questões sobre a performatividade na linguagem do circo. Cultura periférica que resiste aos avanços das mídias e tecnologias, o circo parece ocupar um lugar privilegiado na discussão sobre o tema da performatividade, embora reconheçamos que há um deslocamento temático que geralmente aparta o dois termos. Buscamos aqui pelas possíveis relações entre performatividade, resistência, nomadismo e risco nas artes circenses.

Palavras-chave: Performatividade, Risco, Resistência.

\section{Abstract}

This article seeks to raise questions about performativity in the circus language. Peripheral culture that resists to the advances of media and technology, the circus seems to occupy a privileged place in the discussion on the topic of performativity, although we recognize a thematic shift that usually separates these fields of knowledge. We seek here the possible relationships between performativity, resistance, nomadism and risk in the circus arts.

Keywords: Performativity, Risk, Resistance.

\section{Circo: tradição da resistência}

O picadeiro está vazio. As luzes chamam a atenção da plateia para o alto, onde se vê a lona majestosa do circo; a voz do apresentador ecoa pelo espaço, anunciando a próxima atração: o tão esperado número de trapézio de voos. Os artistas surgem no picadeiro com uma música empolgante e seus figurinos resplandecentes revelam a perfeição de seus corpos; as luzes se voltam para eles que se apresentam ao público com movimentos precisos, marcados, milimetricamente coreografados. Eles movimentam-se rapidamente pelo espaço do picadeiro e logo sobem a longa escada que leva à banquiIha, onde os trapezistas se preparam para seu voo. De um lado, o forte portô que, como o próprio nome sugere, porta os volantes, os voadores. Ele apanha o trapézio e, num movimento brusco, toma impulso e inicia seu movimento pendular. Na banquilha oposta, o volante se prepara, atento, concentrado em 
sua árdua tarefa; de repente, salta, as mãos firmes no trapézio. Depois de pendular por algum tempo, no instante exato em que os dois trapézios estão perfeitamente sincronizados, o volante voa na direção de seu portô, que o ampara, preciso. A plateia aplaude empolgada. $\mathrm{O}$ volante retorna para o primeiro trapézio e de lá para a baquilha; ele reverencia o público, novos aplausos e a cena se repete algumas vezes, com evoluções cada vez mais impressionantes dos acrobatas e reações cada vez mais contundentes da plateia. Depois de algumas repetições e com a crescente empolgação da audiência, o apresentador anuncia: o acrobata tentará o dificílimo salto triplo. As luzes diminuem, os tambores rufam, os acrobatas se preparam. O volante repete toda a sequência de movimentos, mas falha, caindo sobre a rede de proteção. $A$ plateia reage incrédula. Ele retoma seu lugar na banquilha, determinado, e repete toda a sequência novamente; a tensão cresce, todos estão hipnotizados pelo número. Mas, mais uma vez, ele falha. As vozes do público ecoam pelo espaço. Parece que esse é realmente um truque impossível. Mesmo assim, pela terceira vez, anunciado pelo apresentador, o volante retoma seu posto na banquilha. Mais uma vez a tensão cresce, os tambores rufam; ele salta e... finalmente consegue executar o salto triplo! A plateia vai ao delírio.

A cena descrita acima é bem conhecida e foi repetida inúmeras vezes ao longo da história das artes circenses. Apesar de apresentar variações pontuais - e, em alguns casos, radicais - podemos observar na composição dos números circenses a repetição da estrutura apresentada acima: aparição impactante, movimentação baseada numa exageração corporal específica para cada número ou aparelho, figurinos elaborados e uma progressiva exploração do risco. $\mathrm{O}$ desenvolvimento do número circense geralmente cria uma espécie de dramaturgia, na qual os acrobatas evoluem de truques mais simples para outros, mais complexos, difíceis e de maior risco, conduzindo a plateia a um clímax. Conforme o número avança, o risco fica cada vez maior e mais evidente. A espetacularização do risco é explorada ao máximo, pondo em tensão os limites entre o real e o construído artisticamente, como no caso do trapezista acima que, além de sujeitar-se a um risco real, tangível e inegociável - o risco físico que envolve a acrobacia aérea no trapézio de voos - também faz uso do artifício, de forma que o erro "encenado" está a serviço da valorização do acerto posterior. 
Essa estrutura - embora seja apenas uma simplificação esquemática - persiste no tempo e no espaço por força de uma tradição. Uma tradição baseada na transmissão de saberes de geração em geração; saberes que não se limitam à técnica, mas que abarcam toda uma cultura (SILVA, 1996). Uma cultura essencialmente nômade e familiar que encontra no risco e na resistência dois pontos determinantes (FAGOT, 2010). Desta forma, para uma abordagem da cena circense da perspectiva de sua performatividade, torna-se imperativo um aprofundamento sobre os aspectos culturais e sociais dessa comunidade.

Entender a identidade cultural circense passa necessariamente por um entendimento histórico de sua formação. E não se trata de remontarmos ao circo equestre de Ashley, mas de pensarmos como se deram localmente as formações sociais que determinam essa tradição. Ermínia Silva (1996) destaca que na conformação da identidade circense - e principalmente no contexto brasileiro desta tradição - participam uma série de fatores relevantes, relacionados principalmente ao fato de que, em sua massiva maioria, as comunidades circenses se formaram a partir de relações familiares e nômades. Isso acaba por determinar um cotidiano no qual o trabalho e as relações sociais se pautam umas sobre as outras, entrelaçadas e indissociáveis. Dessa forma, a transmissão de conhecimentos técnicos sobre a criação e a replicação de relações do cotidiano têm a mesma importância, ou seja, montar e desmontar a lona é tão importante quanto as técnicas específicas dos números apresentados no picadeiro. O nomadismo como condição básica da comunidade circense também parece relevante nesse contexto.

A condição do nômade - aquele sem residência fixa, sem raízes num lugar geográfico - cria um recorte muito particular do ponto de vista social. Pelbart cita Kafka para localizar a condição do nômade do ponto de vista do pensamento hegemônico: estranhos, com códigos sociais próprios, capazes de se instalarem confortavelmente em meio ao caos, escapando e ao mesmo tempo absorvendo ao que está a sua volta, dentro e fora simultaneamente. O nômade instaura no entorno uma espécie de "lei-esquiza", na qual diretrizes sociais alternativas se estabelecem. $O$ autor também dá ênfase ao fato de que tudo se modifica frente a essa "lei-esquiza": a organização familiar, a economia, a linguagem, tudo enfim que concerne ao convívio social. 
Não parece fortuito que o circo tenha abrigado tantas formas diferentes da expressão artística, das acrobacias ao freak show. Ao mesmo tempo abre-se o precedente ao que Charles Feitosa (2007) chama de "a comunidade dos cunhados": uma comunidade em que o que faz a ligação entre os indivíduos não é o mero parentesco sanguíneo necessariamente, mas que se estabelece em função da escolha da parte dos elementos que a compõem, ou seja, de uma comunidade na qual as condições não são dadas a priori, mas se dispõem a um devir. Isso parece explicar o fato de a tradição circense apresentar-se de forma tão aberta, porosa e sem limites definidos ao que está fora da fronteira comunitária.

Emmanuel Wallon (2009) destaca que a tradição do picadeiro se dá no trânsito, tal qual o nomadismo como conceito se impõe:

[...] a linguagem do circo se elabora em uma dupla negociação: de um lado com a tradição, aquela que foi constituída durante o século XIX e codificada no princípio do século XX; por outro lado com as artes vizinhas, em que os inventores modernos azucrinam de bom grado esse primo ao charme brutal. (p. 18)

Em outras palavras, estamos falando de uma tradição que está em constante diálogo com seu contexto, criando adaptações pertinentes a cada espaço, a cada comunidade. Essa capacidade de adaptação e adequação remete tanto ao conceito deleuziano de nomadismo quanto às possibilidades de relação com o conceito de resistência.

\section{Resistência e risco}

Interrompemos as considerações sobre a tradição circense abrindo um parêntese importante: sobre a resistência. $\mathrm{O}$ que se entende por resistência? No campo da física, resistência é a força que se opõe ao movimento de um sistema. Semanticamente pensamos a resistência como oposição a ou contra alguma coisa, ou seja, como reação, recusa. Mas a resistência como conceito extrapola esses limites; Charles Feitosa (2007) aponta para a possibilidade de resistência como uma atitude de re-insistência, tomando o prefixo "re" como possibilidade de duplicação, que tem tanto o sentido de replicação quanto o 
de firmeza e persistência. Para o autor a resistência assume a imagem do surfista, que faz uso de uma força maior (a onda) para gerir seus próprios movimentos: ele não se mantém fixo, mas tampouco se deixa levar completamente pelo movimento exterior; ele abre as possibilidades de manobra frente a um poder maior, escapando e assimilando simultaneamente a força exterior. Resistir é dizer sim e não ao mesmo tempo, criando movimentos próprios a partir de um contexto maior e irresistível.

O recorte proposto por Feitosa relaciona-se com as teorias deleuzianas sobre a sociedade de controle, que pressupõem um deslocamento tanto dos meios de produção quanto das questões sociais em relação ao modelo disciplinar proposto por Foucault; trata-se, pois, de uma abordagem do capitalismo tardio, que acarreta consequências sociais bastante características: é o que Bauman (2007) chama de "modernidade líquida" e Beck (2010) nomeia como "sociedade de risco." E é inegável que a cultura circense nesse contexto sofre transformações importantes que acarretam novas formas de organização do trabalho e da vida cotidiana. Não iremos nos deter muito nesse ponto, mas parece relevante a observação feita por Ermínia Silva (2009) de que o número de circos em atividade no Brasil tem caído substancialmente, principalmente a partir da década de 1980; em contrapartida, artistas do picadeiro têm participado cada vez mais de processos de criação deslocados do ambiente da lona, ocupando espaços no teatro, na dança e nas artes performativas em geral.

A subsistência da tradição circense sempre dependeu de sua notável capacidade de adaptação, mas no contexto da sociedade de risco esse sentido de adequação é testado ao limite. Fica evidente que a cultura circense é uma cultura de resistência por excelência, tanto no sentido da re-insistência - mantendo quase intactas as formas de transmissão de conhecimentos e os modos de produção artística - quanto no sentido de uma "forma especial de enfrentar o poder" (FEITOSA, 2007, p. 26), que diz sim e não ao mesmo tempo, mantendo-se dentro e fora do sistema hegemônico simultaneamente, cooptado e marginalizado. A resistência do circense é como a do surfista, que não luta obstinadamente contra a onda e nem tampouco se deixa levar completamente por ela; ele "(...) tem a sabedoria paradoxal de respeitar e aproveitar a força, a velocidade e a intensidade das ondas" (Ibid., p. 29). A resistência do circo parece residir no movimento, no trânsito entre convenção e ruptura. 
Gilles Deleuze diz que todo ato de criação é um ato de resistência e que a resistência sempre é relativa à morte. Embora essa seja uma afirmação complexa, difícil de ser assimilada num único sentido, quando transportamos essa ideia para o contexto do circo temos a possibilidade de criar uma série de desdobramentos. Em primeiro lugar podemos destacar a relação da criação dos números - em especial os de caráter acrobático - com o risco físico que, em última instância, pode levar à morte. $O$ contexto circense propõe uma reflexão que toma literalmente as palavras de Deleuze, radicalizando a atitude de resistência como atitude e existência. Camille Dumoulié (LINS, 2007) alinha uma série de conceitos fundamentais do pensamento deleuziano, a partir do que chama de um "devaneio filosófico", sobre a resistência: linhas de fuga, devir, nomadismo e máquina de guerra. Embora nossa reflexão seja ainda incipiente e não tenhamos aqui as condições para um aprofundamento sobre esses conceitos, temos aí algumas pistas importantes que nortearão a continuidade de nossos estudos sobre este tema.

O risco como devir de morte está obstinadamente presente na poética e estética do circo. Paradoxalmente, é como devir de vida que o risco se afirma na cena circense. Quanto maior a exposição ao risco, mais interesse é despertado na audiência. Buscar a origem da relação das artes circenses com o risco parece uma tarefa árdua e desgastante demais para esta breve reflexão e remonta às próprias origens do circo como linguagem e como organização social e comunitária. O que importa aqui é menos a apreensão da originalidade dessa relação e mais uma reflexão sobre os desdobramentos possíveis advindos dos atravessamentos entre risco e arte circense. Cabe notar que o risco nesse contexto não tem apenas um único sentido, mas se desdobra sobre diversos campos. E não é apenas o aspecto material do risco que importa para esta discussão, mas também o seu caráter imaterial, impalpável, mas perfeitamente tangível.

Propomos então três abordagens distintas e complementares do risco, tomando emprestadas as definições do termo presentes em outros campos do conhecimento que não apenas o da arte - principalmente na sociologia e filosofia. Destacamos então o risco físico, o risco social e o risco artístico. Em cada um dos enfoques do termo o sentido se mantém - o de probabilidade de dano e exposição ao perigo -, mas encerra implicações específicas. No 
primeiro caso implica na integridade corporal, podendo comprometer mesmo a própria vida do artista (devir de morte). O risco social diz respeito tanto às condições da produção artística em termos mercadológicos quanto ao reconhecimento do artista e da obra como tais. O risco artístico se relaciona com a transgressão dos limites entre obra de arte e vida, com a possibilidade do comprometimento da obra de arte como tal, que se arrisca a descaracterizar-se na medida em que se apagam as fronteiras entre real e artifício. Cabe observar que a expressão "risco artístico" aparece como portadora de fortes vínculos com a berlinda social da classe artística francesa - em especial a comunidade circense do final da década de 1980 (WALLON, 2009) -, além de abrigar um sentido ligado ao risco físico sofrido pelos artistas circenses e também à possível descaracterização do circo com o advento do então chamado Novo Circo.

É notável que o circo - como linguagem e como organização social - guarda fortes vínculos com cada um dos desdobramentos do risco que propusemos acima. No caso do risco físico, temos uma primeira camada, mais evidente à primeira vista, uma vez que esse parece ser um dos principais e mais explorados recursos da linguagem circense. Emmanuel Wallon (2009) destaca:

Concretamente exposto ao perigo das feridas (fratura, mordida, queimadura, escoriação), sem falar do risco de contusão simbólica compartiIhado com os agentes de outras especialidades, os intérpretes da pista convidam o medo para o círculo da lona, em companhia do júbilo que provoca o repentino relaxamento de sua tensão. No cerne dos dispositivos de representação eles introduzem a dupla instável que forma o riso e o temor. (p. 16)

Retomando a perspectiva social e cultural dos artistas circenses, vivemos um momento no qual convivem tanto artistas ditos "tradicionais" (SILVA, 1996) - geralmente nascidos e criados na lona, de condição nômade e organização familiar - quanto artistas que não vivem sob a lona, formados por escolas de circo - que geralmente não são descendentes de famílias circenses, de condição sedentária e autônoma ou organizados em coletivos ou grupos. Essa condição original parece acarretar consequências muitíssimo profundas e complexas em relação ao risco social envolvido na atividade circense. Con- 
tudo, por se tratar de uma discussão muito extensa, não nos aprofundaremos nesse ponto; mesmo assim vale um apontamento preliminar: sobre o nomadismo como fator determinante nos modos de produção, aprendizagem e criação circenses. Artistas "tradicionais" e "não-tradicionais" acabam por se diferenciar entre si em função de seus processos, uma vez que a vida cotidiana do artista - nômade ou sedentário - acaba por criar situações sociais muito distintas.

\section{Performatividade e risco}

A abordagem do risco artístico na cultura circense nos aproxima de questionamentos acerca da performatividade. Entendemos o risco artístico como uma espécie de transversalidade que atravessa arte e vida, borrando seus limites. Uma radicalização das consequências possíveis decorrentes desse apagamento da fronteira entre vida e arte é a total pulverização da obra - e mesmo do artista - como tal, que deixa de ser produto de um processo de criação e transforma-se, simplesmente, em processo. Em relação à performatividade, Josette Féral (2009a) aponta que há um sentido similar: "A performatividade não é um fim em si mesmo, uma realidade concreta ou acabada mas um processo. Ela é construção (uma realidade $X$ como performance) e reconstrução (reconhecimento intelectual das etapas dessa construção)" (p. 66).

Contudo, no caso do artista circense, temos também um desdobramento imediato do risco físico em risco artístico, uma vez que a exposição deliberada ao perigo não é uma construção (no sentido de sua artificialidade), um truque, nem tampouco virtualidade, mas pura realidade. $O$ risco em cena parece ter a capacidade de trazer o real para junto do artifício, sobrepondo-os. Voltemos para o exemplo do trapezista de voos: apesar de toda a construção, de toda formalização artificial evocada pelos movimentos marcados e exagerados do corpo do acrobata, o espectador não consegue por um instante se distanciar da irrevogável materialidade do risco. A gravidade, o peso, o movimento, são todos elementos tangíveis e inegociáveis a que todos os corpos estão sujeitos; ignorar essa condição é quase impossível, pois são condições da própria realidade. O risco sobrepõe à ação cênica a ação real, que pode ser elaborada e construída artisticamente, mas que não perde por um segundo o vínculo com a realidade. 
O risco artístico parece pressupor um engajamento total do artista, de forma que obra e sujeito se misturem, se confundam, fundindo arte e vida numa mesma experiência. Por seu próprio caráter de jogo eterno entre equilíbrio e desequilíbrio, de limiar de condições praticáveis para o próprio jogo, o risco nos aproxima das artes cênicas em geral (GOUDARD, 2009) e especialmente da performance, que encerra em si a própria noção de risco. Féral (2009b) observa:

Eu dizia que havia duas ideias principais no cerne da obra performativa. A segunda consiste no engajamento total do artista colocando em cena o desgaste que caracteriza suas ações (Nadj, Fabre). Não se trata necessariamente de uma intensidade energética do corpo no modelo grotowskiano, mas de um investimento de si mesmo pelo artista. Os textos evocam a "vivacidade" (liveness) dos performers, de uma presença fortemente afirmada que pode ir até uma situação de risco real e implica em um gosto pelo risco. (p. 207, grifos do autor)

Nesse ponto observamos um cruzamento-atravessamento entre as definições sobre os conceitos de performatividade e risco artístico. Ambos afirmam-se como processos, evadem a fronteira entre arte e vida e pressupõem um engajamento total do artista. Contudo, parece ser prematuro afirmar qualquer conclusão. No lugar de respostas, esta reflexão nos leva a novas perguntas: uma vez postos em tensão os vetores entre resistência e risco, por um lado, e performatividade e risco, por outro, resta-nos questionar sobre as possibilidades de uma oposição entre resistência e performatividade. Podemos abordar o risco como traço performativo da resistência? A perspectiva da cultura circense como cultura de resistência parece relacionar risco e performatividade de uma forma muito particular, colocando num mesmo plano os questionamentos éticos, estéticos, poéticos e políticos: arte e vida sob a mesma lona. 


\section{Referências bibliográficas}

BAUMAN, Z. Vida líquida. Rio de Janeiro: Jorge Zahar, 2007.

BECK, U. Sociedade de risco: rumo a uma outra modernidade. São Paulo: Editora 34, 2010.

FAGOT, S. Le cirque: entre culture du corps et culture du risque. Paris: L'Harmattan, 2010.

FEITOSA, C. Revolução, revolta e resistência: a sabedoria dos surfistas. In: LINS, D. (Org.). Nietzsche/Deleuze: arte, resistência. Rio de Janeiro: Forense Universitária; Fortaleza: Fundação de Cultura, Esporte e Turismo, 2007.

FÉRAL, J. Por uma poética da performatividade: o teatro performativo. Revista Sala

Preta, São Paulo, v. 9, n. 1, p. 197-210, 2009a.

Performance e performatividade: o que são os estudos performáticos? In: MOSTAÇO, E. et al. (Orgs.). Sobre performatividade. Florianópolis: Letras Contemporâneas, 2009b.

GOUDARD, P. Estética do risco: do corpo sacrificado ao corpo abandonado. In: WALLON, E. (Org.). O circo no risco da arte. Belo Horizonte: Autêntica, 2009.

LINS, D. (Org.). Nietzsche/Deleuze: arte, resistência. Rio de Janeiro: Forense Universitária; Fortaleza: Fundação de Cultura, Esporte e Turismo, 2007.

SILVA, E. O circo: sua arte e seus saberes: o circo no Brasil do final do século XIX a meados do século XX. 1996. Dissertação (Mestrado em História) - Universidade de Campinas, Campinas, 1996.

SILVA, E.; ABREU, L. A. Respeitável público... o circo em cena. Rio de Janeiro: Funarte, 2009.

WALLON, E. (Org.). O circo no risco da arte. Belo Horizonte: Autêntica, 2009.

Recebido em 18/03/2016

Aprovado em 30/05/2016

Publicado em 01/07/2016 